\title{
TECENDO CAMINHOS E AFIRMANDO SENTIDOS ENTRE CIDADANIA, ESPAÇO E GEOGRAFIA ESCOLAR
}

\author{
Weaving paths and asserting meanings among \\ Citizenship, Space and School Geography
}

\author{
Amélia Cristina Alves Bezerra \\ Professora adjunto da Universidade Federal Fluminense - UFF \\ amelliacristina@uol.com.br
}

Artigo recebido em 27/06/2016 e aceito para publicação em 20/11/2016

DOI: $10.12957 /$ tamoios.2016.23532

\begin{abstract}
Resumo
"Formar para a cidadania" tornou-se um termo recorrente nos vários campos discursivos, inclusive no âmbito da educação, e, embora, reconheçamos e reafirmamos sua importância como um horizonte da luta por igualdade social e reconhecimento, seu uso demasiado e sem acompanhamento de reflexões históricas e políticas tem contribuído para certo esvaziamento do conceito. Esse diagnóstico nos coloca diante da necessidade de pensar sobre os elementos históricos que conformaram os referenciais de cidadania no Brasil, e o que revelam as experiências históricas e o papel dos saberes escolares, especialmente as contribuições da geografia escolar, nesse processo de construção. Essas inquietações norteiam este artigo, que objetiva trilhar um caminho reflexivo entre espaço, cidadania e geografia escolar, pois, embora ainda que a dimensão espacial seja fundamental para pensar a sociedade, ela tem sido negligenciada na construção das noções de cidadania presentes na escola. Tal reflexão encontra-se dividida em três momentos: no primeiro, introduzimos a discussão sobre o papel do tempo e do espaço na compreensão das relações sociais; em seguida, aproximamo-nos das dimensões históricas e teóricas que conformaram a ideia de cidadania no Brasil e sua relação com o espaço; por último, tecemos um caminho entre cidadania, espaço e geografia escolar.
\end{abstract}

Palavras-chave: Espaço; Cidadania; Geografia Escolar.

\begin{abstract}
"Training for citizenship" has become a recurring term in various discursive fields, including the education one, and, although we recognize and reaffirm its importance as the horizon for the fight for social equality and recognition, its intensive use without monitoring the historical and political considerations has contributed to a rather emptiness of the concept. This diagnosis puts us before the need to think about the historical elements that shaped citizenship references in Brazil, and what do the historical experiences and the role of school knowledge reveal, especially the contributions of school geography in this construction process. These concerns guide this article, which aims to tread a reflective path between space, citizenship and school geography, since, although the spatial dimension is fundamental when thinking about society, it has been neglected in the construction of notions of citizenship present in school. This reflection is divided into three stages: on the first, we introduce the discussion on the role of time and space in the understanding of social relations; then we approach the historical and theoretical dimensions that shaped the idea of citizenship in Brazil and their relation to space. Finally, we weave a path between school citizenship, school space, and school geography.
\end{abstract}

Keywords: Space. Citizenship. School Geography. 


\section{Introducão}

A espacialidade humana foi historicamente marginalizada - ou negligenciada como uma dimensão fundamental no processo de compreensão das relações sociais. Tal afirmação, desenvolvida por Soja (1993) e afirmada por Massey (2008), coloca-nos diante da compreensão de que, tanto na filosofia quanto nas ciências sociais, com raras exceções, houve um privilégio do tempo e da historicidade como elementos explicativos da realidade social. Essa dimensão da espacialidade também não tem sido desenvolvida de forma satisfatória no âmbito dos saberes escolares, inclusive pela geografia escolar.

As reflexões apontadas por Yves Lacoste (1988) na década de 1970 nos dão conta de que a "geografia dos professores", que apareceu há menos de um século, tornou-se um discurso ideológico no qual uma das funções inconscientes é a de mascarar a importância estratégica dos raciocínios centrados no espaço, dissimulando, aos olhos da maioria, a eficácia dos instrumentos de poder que são as análises espaciais. Apesar desse diagnóstico crítico acerca do negligenciamento do espaço, enquanto elemento de interpretação da sociedade, é preciso ter clareza de que "não existe sociedade a-geográfica, assim como não existe espaço geográfico a-histórico", afinal, o espaço geográfico é constituído pela relação que os diferentes sujeitos estabelecem entre si com a sua materialidade (PORTO-GONÇALVES, 2002, p. 22). Tais preocupações apontam para um equilíbrio entre tempo e espaço na teoria social crítica. Nesse sentido, a "descoberta" do espaço como categoria de análise dos problemas sociais do nosso tempo no fim do século XX tem resultado em um grande revigoramento de interesse pelos conceitos e categorias que buscam explicar a geograficidade humana.

Esse revigoramento do debate do espaço, nas ciências sociais, afirma a compreensão da espacialidade como dimensão fundamental para o entendimento dos fenômenos sociais, a exemplo da globalização, da urbanização das cidades, dos problemas ambientais, das questões territoriais e tantas outras que emergem na sociedade contemporânea e que reforçam a compreensão do espaço como condição, meio e produto das relações sociais (LEFEBVRE, 1991). Embora a dimensão espacial seja fundamental para pensar a sociedade, a mesma não tem sido levada em conta para pensar a cidadania na escola, resultando numa certa alienação da própria noção de cidadania que, por vezes, se torna algo abstrato para professores e alunos envolvidos no processo de ensino-aprendizagem.

Dessa forma, torna-se urgente pensar quais são as bases teóricas, políticas e históricas a partir das quais a ideia de cidadania foi construída no Brasil, e como essas noções vêm sendo trabalhadas no âmbito da escola, bem como as contribuições da Geografia Escolar nesse processo. Essas questões norteiam o presente trabalho ${ }^{1}$, que tem como objeto de reflexão uma análise das relações existentes entre espaço, cidadania e geografia escolar. Esta, embora alvo de várias reflexões e análises, ainda permanece como uma questão a ser pensada e tensionada na sociedade brasileira, onde, por vezes, afirma-se o caráter racista e desigual que marca o espaço e os corpos, interpelando a geografia escolar e acadêmica e colocando esse saber no centro do debate sobre cidadania.

\section{Cidadania e espaco: aproximacões teóricas e históricas}

Cidadania se tornou um termo recorrente nos documentos que orientam os objetivos da educação, do planejamento territorial e urbano e de tantos outros campos discursivos que envolvem projetos voltados para a sociedade. Identificamos sua presença nas diretrizes curriculares, nos parâmetros curriculares, nos projetos políticos 
pedagógicos, nos livros didáticos, nos planejamentos diários, entre outros. "Formar para a cidadania" tem sido a solução encontrada para os rumos da educação e, muito embora reconheçamos a sua importância, seu uso demasiado tem esvaziado a dimensão política e social do conceito. Mas quais são os elementos que conformaram a ideia de cidadania no Brasil? O que revelam as experiências históricas sobre a construção da cidadania na sociedade brasileira? Quais seriam as contribuições da Geografia nessa construção?

A cidadania enquanto fenômeno histórico e geográfico se realizou de modo distinto nas diferentes sociedades. No Brasil, o referencial de cidadania que perseguimos foi construído a partir das interpretações elaboradas por Marshall ${ }^{2}$. Esse referencial europeu tem nos orientado no julgamento das condições sociais a que as diferentes sociedades têm sido submetidas em cada momento histórico. Contudo, precisamos adicionar a esse processo nossos referenciais de justiça social, analisando, inclusive, os parâmetros propostos pelo ocidente que, muitas vezes, mostram-se um tanto quanto distantes. Nesse sentido, como bem destaca Carvalho (2002), uma cidadania plena, que combine o direito à liberdade, participação e igualdade para todos, é um "ideal" desenvolvido no ocidente, podendo haver desvios e retrocessos não previstos nos referenciais construídos por Marshall, nos quais o percurso inglês foi apenas um dentre outros. As palavras de Milton Santos (2012) reforçam essa perspectiva:

\begin{abstract}
A cidadania pode começar por definições abstratas, cabíveis em qualquer tempo e lugar, mas para ser válida deve poder ser reclamada. A metamorfose dessa liberdade teórica em direito positivo depende de condições concretas, como a natureza do Estado e do regime, o tipo de sociedade estabelecida e o grau de pugnacidade que vem da consciência possível dentro da sociedade civil em movimento. É por isso que, desse ponto de vista, a situação dos indivíduos não é imutável, está sujeita a retrocessos e avanços (SANTOS, 2012, p.20).
\end{abstract}

Outro aspecto importante derivado da natureza histórica da cidadania é que esta se desenvolveu dentro do fenômeno também histórico a que chamamos de Estadonação. A luta pelos direitos, todos eles, sempre se deu dentro das fronteiras geográficas e políticas do Estado-nação. Trata-se de uma luta política nacional, e o cidadão de que dela surge também é nacional. Isso quer dizer que a construção da cidadania tem a ver com a relação da sociedade com o Estado e com a nação (CARVALHO, 2002).

Nessa perspectiva, Gomes (2002) destaca que as composições políticas resultantes do momento revolucionário do final do século XIX reconheceram, em sua maior parte, a responsabilidade do Estado em fornecer à população as condições mínimas de vida, como abrigo, educação, alimentação e segurança, entre outras, para que a cidadania pudesse ser exercida por todos em igualdade de condições. Nesse processo, percebe-se que o conceito de cidadania mudou junto com a relação do indivíduo com o Estado e com sua coletividade e que, hoje, a cidadania se refere, cada vez mais, a um significado de inclusão, baseado em ideais de isonomia garantidos pela lei.

Contudo, as relações entre Estado, sociedade e nação vêm sofrendo uma série de mudanças que refletem na construção dos referenciais de cidadania, sobretudo nos países "orientadores" desses referenciais. A aceleração da globalização e o recrudescimento das relações capitalistas com orientação neoliberal coloca-se como um dos motores dessas mudanças que têm levado à redução do papel do Estado em detrimento dos organismos e mecanismos de controle internacionais. Na União Europeia, os governos nacionais perdem poder e relevância diante dos órgãos políticos e burocráticos supranacionais. Os cidadãos ficam cada vez mais distantes de seus 
representantes e as grandes decisões políticas e econômicas são tomadas, muitas vezes, fora do âmbito nacional.

A exigência de reduzir o déficit fiscal tem levado governos de todos os países a reformas no sistema de seguridade social. Essa redução tem resultado sistematicamente em cortes de benefícios e na descaracterização do estado de bem-estar, referência de um equilíbrio, mesmo que precário, entre capital e direito trabalhista. A competição feroz que se estabeleceu entre as empresas também contribuiu para a exigência de redução de gastos via poupança de mão de obra, gerando um desemprego estrutural difícil de eliminar. Isso, por sua vez, no caso da Europa, leva a pressões contra a presença de imigrantes africanos e asiáticos e contra a extensão a eles de direitos civis, políticos e sociais. O pensamento liberal renovado volta a insistir na importância do mercado como mecanismo autorregulador da vida econômica e social e, como conseqüência, na redução do papel do Estado (CARVALHO, 2002).

No entanto, sempre é preciso lembrar que a cidadania não se constrói apenas no plano jurídico do direito positivo ancorado no Estado, mas é exercida a partir das práticas sociais cotidianas. Assim, reconhecemos as várias lutas e protestos exercidos na conquista dos direitos sociais, políticos e civis. As rebeliões de escravos, as insurreições populares, as lutas urbanas e agrárias que derivaram em ocupações organizadas de terras e a organização dos trabalhadores das fábricas são algumas expressões das tensões com o Estado e com o capital no processo de construção e territorialização da cidadania e dos modos de ser.

As reflexões feitas por Magalhães (2003) chamam a atenção para os matizes contidos nos referenciais de cidadania que congregam e apontam para dois eixos de debate. O primeiro eixo sublinha a ampliação dos direitos que se expandiriam e se universalizariam tendo como pressuposto a igualdade. Os comentaristas dessa linha tomam como crítica central o mascaramento da luta de classes, mas também aqui o debate é matizado, pois há aqueles que tomam exatamente a postura antagônica, qual seja: o avanço da cidadania é uma conquista da luta de classes. O segundo eixo reflete acerca da cidadania na chave do direito à diferença. O pressuposto aqui é o reconhecimento das particularidades e das identidades até então subjugadas. A cidadania passa a ter adjetivos de acordo com o pertencimento autodeterminado de cada indivíduo ou grupo. $\mathrm{O}$ outro, no processo de fragmentação social, passa a ter seu peso ontológico reconhecido (BEZERRA E CAVALIERI, 2014).

Os direitos à igualdade e ao reconhecimento da diferença, nuances da construção da cidadania, têm se afirmado no conjunto de lutas travadas por justiça social no Brasil. Ao discutir os movimentos sociais na sociedade contemporânea, Cruz (2013) reforça as pautas ligadas ao reconhecimento e à redistribuição presentes nas lutas sociais contemporâneas, a exemplo dos povos indígenas, quilombolas e comunidades tradicionais, mas também na via campesina e tantas outras lutas que vêm afirmando o território como dimensão de sobrevivência e existência material, cultural e política. Nesse cenário de lutas, chama a atenção para o fortalecimento do movimento feminista, movimento negro, movimento gay e outros que têm afirmado a necessidade do reconhecimento e respeito à diferença.

Cruz (2013) chama a atenção também para os desafios que permeiam as lutas dos movimentos sociais contemporâneos, bem como as análises que vêm sendo feitas no plano político e epistemológico e que tendem a separar redistribuição de reconhecimento. Nesse sentido, apresenta a seguinte preocupação: como incluir essa nova sensibilidade política que valoriza a diferença e as lutas por reconhecimento sem abandonar a agenda distributiva e igualitária tão importante e urgente em nossa sociedade? 
Ao estabelecer a relação entre as lutas dos movimentos sociais e a construção da cidadania, Holston (2013) afirma que, apesar de a luta pela igualdade e pelo direito à diferença ter sido alvo das lutas dos diversos movimentos sociais e das suas negociações com o Estado e o capital, esses elementos têm resistido na construção da cidadania no Brasil. Tal herança contribuiu para que a cidadania se caracterizasse pela administração das diferenças sociais, legalizando-as de maneira que legitimam e reproduzem a desigualdade. Ao longo dessa construção, prevaleceu "um regime de privilégios legalizados e desigualdades legitimadas" que persistiu sob os governos colonial, imperial e republicano, prosperando sob a monarquia, a ditadura e a democracia (HOLSTON, 2013, p.13).

Resistências, confrontos e negociações entre a sociedade civil e o Estado têm marcado a luta pela cidadania no Brasil, que nasce e floresce nesse embate, e não somente na representação estrita por intermédio do Estado, como bem nos lembra Damiani (1999). Nesses embates e confrontos, a dimensão espacial tem ocupado, cada vez mais, uma centralidade, expressa, na cidade, através das lutas dos movimentos sociais por moradia, mobilidade, lazer e outros direitos e, no campo, pela pauta dos povos indígenas, quilombolas, comunidades tradicionais da via campesina e outros que colocam o espaço rural - as lutas por territórios - no centro da disputa por território.

É preciso compreender que as práticas sociais se dão no e pelo espaço, e não fora dele ${ }^{3}$. A herança dessa desigualdade se expressa tanto no espaço urbano quanto no rural $^{4}$. Desse modo, é preciso afirmar que o espaço ocupa uma centralidade no exercício da cidadania, sendo a condição e o meio desse exercício (BEZERRA e CAVALIERI, 2014). Em sua obra A Condição Urbana, Gomes (2002) defende que o reconhecimento do exercício da cidadania desde as práticas sociais cotidianas requer o tratamento do espaço público como uma categoria de análise ${ }^{5}$. Entende-se que o espaço público, bem como a cidade e o campo, pode ser compreendido e estudado através da análise da vida cotidiana como prática socioespacial (CARLOS, 2007; GOMES, 2002).

Assim, a dimensão espacial precisa ocupar as práticas e reflexões que são desenvolvidas no universo escolar e, especialmente, na geografia que se ensina. Afinal, um dos objetivos da Geografia na escola é construir uma consciência espacial por meio da qual possamos compreender a sociedade, já que "o cidadão é o cidadão de um lugar, de um espaço, especialmente, de uma nação" (DAMIANI, 1999, p. 59). Cabe à Geografia, então, formar um sujeito que saiba se posicionar no espaço, no lugar e na nação da qual faz parte, sendo esse o sentido de aprender e ensinar geografia, como nos propõe Renato Emerson dos Santos (2007). É nessa direção que se afirma o entrelaçamento entre cidadania, espaço e Geografia.

\section{$\underline{\text { Tecendo caminhos entre cidadania, espaco e geografia escolar }}$}

O final da década de 1980 e a década de 1990 viram surgir no Brasil a centralidade da cidadania nos discursos da sociedade civil, nas lutas dos movimentos sociais, nos documentos que orientam as políticas públicas - como é o caso do plano diretor das cidades - e em outros tantos projetos, a exemplo dos documentos oficiais oriundos das reformas educacionais. Um dos marcos dessa centralidade pode ser reconhecido na Lei de Diretrizes e Bases (LDB, 1996) e nos Parâmetros Curriculares Nacionais (PCN, 1999). O conceito/tema da cidadania é acionado nos objetivos que norteiam os Parâmetros Curriculares, em todas as disciplinas e níveis: 
dia, atitudes de solidariedade, cooperação e repúdio às injustiças, respeitando o outro e exigindo para si o mesmo respeito.

O conceito de cidadania também é acionado na apresentação dos Parâmetros Curriculares dedicados aos temas transversais:

O compromisso com a construção da cidadania pede necessariamente uma prática educacional voltada para a compreensão da realidade social e dos direitos e responsabilidades em relação à vida pessoal, coletiva e ambiental. Nessa perspectiva é que foram incorporadas como Temas Transversais as questões da Ética, da Pluralidade Cultural, do Meio Ambiente, da Saúde e da Orientação Sexual.

De acordo com Chauí (s/d), a proposta de reforma educacional não nasceu autodeterminada e soberana. Ela surgiu de organizações mundiais e financeiras, gestada sob a égide da modernização. Nesse processo, a questão educacional foi tratada como "questão técnica" a ser resolvida pelo aparelho estatal competente. Visava-se certa padronização e adequação do currículo à proposta, focada na preocupação com a formação do aluno cidadão ${ }^{6}$ (BEZERRA E CAVALIERI, 2014).

Um caminho profícuo para entender os meandros da disciplina geografia escolar no seio da consolidação das reformas do sistema de ensino no Brasil e em outros cantos do mundo é descortinar os embates e escolhas político pedagógicas no campo do currículo. As questões acerca do currículo escolar e das propostas para o ensino de geografia estão intimamente ligadas ao projeto de cidadão ${ }^{7}$ que vem sendo forjado, sendo necessário, portanto, reconhecer qual projeto de cidadania está explicitamente desenhado. Nesse projeto, a ser amplamente debatido, ampliado, refutado ou estendido, vê-se a geografia escolar contribuir com a dimensão da espacialidade, com a leitura do espaço em suas diversas escalas.

$\mathrm{Na}$ tentativa de responder a essa demanda, muitos projetos pedagógicos desenvolvidos atualmente nas escolas têm como objetivo a formação de um aluno cidadão, reconhecido como aquele que pensará o lugar onde vive e contribuirá para suas mudanças socioespaciais. Apesar de tais objetivos, mais ou menos explícitos, a dimensão espacial, muitas vezes, é negligenciada pelos diferentes representantes das ciências humanas, embora tal dimensão seja fundamental para pensarmos a cidadania (BEZERRA \& FEU, 2013, p. 134). Nesse sentido, as palavras de Gomes (2002, p. 134) advertem:

[...] podemos afirmar sem medo que, a despeito do pouco relevo explícito da questão territorial no discurso de alguns especialistas sobre a questão da cidadania, o território, sua dinâmica, sua configuração, sua constituição e natureza são assinalados como elementos fundamentais na redefinição das relações políticas.

O espaço como produção social e seus recortes, a exemplo da questão territorial destacada por Gomes (2002), são importantes no processo de construção e exercício da cidadania ao colocar-se como dimensão que precisa ser enfrentada nas escolas, pois, enquanto materialização das relações sociais, o espaço é um produto histórico e social. Na perspectiva de Santos (2002), o espaço é formado por um conjunto indissociável, solidário e, também, contraditório dos sistemas de objetos - materialidade - e sistemas de ações - as relações sociais. Partindo dessa compreensão, os sujeitos, através das suas ações e práticas cotidianas, carregam consigo um potencial de produção, reconfiguração e significação espacial. 
Dessa forma, o espaço escolar, especialmente o público, em sua relação com a comunidade, apresenta-se como um ponto de partida estratégico para pensar a produção social do espaço, dimensão fundamental na formação de uma consciência cidadã, visto que a escola é um dos primeiros espaços sociais produzidos e vividos pelos sujeitos no qual se manifestam as desigualdades e as diferenças produzidas socialmente.

Cabe à geografia escolar, portanto, encontrar caminhos metodológicos para abordar a produção do espaço no cotidiano da sala de aula. Para tanto, faz-se necessário e urgente a superação do enciclopedismo, do uso da memória, dos exercícios de fixação e das práticas que não valorizam a aprendizagem significativa e fragilizam o debate acerca da geografia escolar (LÉSTEGAS, 2012), reiterando esse saber como uma descrição do mundo maçante e simplória (LACOSTE, 1988).

Damiani (1999, p. 52), nessa direção, reforça que seria definido como cidadão aquele que conseguisse viver a condição espacial enquanto espaço social, reconhecendo-se na sua produção:

É infracidadão aquele que não reconhece em sua obra e vivencia, de forma totalmente alienada, suas relações humanas sendo seu espaço vivido reduzido ao espaço geométrico. Essa restrição da vivência não atinge somente os mais pobres, embora alcance preferencialmente. Os termos da produção do espaço envolvem a redefinição da qualidade dos espaços produzidos. Prevalecem os espaços redutores, que já não são espaços de vida, mas espaços ressecados, de relações sociais e afetivas reduzidas.

Santos (2012, p.81) acrescenta ainda que:

[...] quando o homem se defronta com um espaço que não ajudou a criar, cuja história desconhece, cuja memória lhe é estranha, esse lugar é a sede de uma vigorosa alienação. Mas o homem é um ser dotado de sensibilidade, busca reaprender o que nunca lhe foi ensinado, e vai pouco a pouco substituindo a sua ignorância do entorno pelo conhecimento, ainda que fragmentário. $\mathrm{O}$ entorno vivido é lugar de uma troca, matriz de um processo intelectual.

Formar sujeitos para o exercício da cidadania exige do professor atenção ao mundo do aluno em seu cotidiano de sala de aula, o que implica, então, "o uso e o emprego do tempo cotidiano, a prática espacial como obra social, coletiva e individual" (DAMIANI, 1999, p. 60). Exige também maior atenção às possibilidades de trabalho interdisciplinar com as outras matérias do currículo, no sentido de potencializar as ações de um projeto político pedagógico que inclua objetivos sociais e concepções explícitas de formação cidadã (CAVALCANTI, 2010).

Todas essas ações precisam ser orientadas por alguns princípios, dentre os quais a compreensão de que o consumidor não é o cidadão, como nos alerta Santos (2012), pois, quando confundimos cidadão e consumidor, a educação, a moradia, a saúde e o lazer aparecem como conquistas pessoais, como mercadoria e não como direitos sociais. Para tanto, é preciso ficar atento ao poder contagiante, alienante e perverso que o consumo tem assumido na sociedade atual. $\mathrm{O}$ eleitor também não é, forçosamente, o cidadão, pois o eleitor pode existir sem que o indivíduo realize inteiramente suas potencialidades como participante ativo e dinâmico de uma comunidade.

Partindo dessas reflexões, caberia à geografia escolar, através das suas mediações pedagógicas contribuir para a construção de uma consciência espacial, de um sentimento de pertencimento e compromisso das crianças, jovens e adultos com o espaço produzido socialmente. Quando nos reconhecemos no espaço, no lugar em que vivemos, no território que lutamos e ocupamos, conseguimos reconhecer nossa posição 
no mundo, tomar posição nesse mundo e, ainda, colocar-se politicamente em seu processo de reconstrução, como nos alerta Renato Emerson dos Santos (2007).

Esse posicionamento diante do mundo exigirá um conhecimento do espaço físico em que estamos inseridos, da relação que estabelecemos com a natureza, assim como das estruturas econômicas, políticas e sociais que organizam as diferentes formas espaciais - como os espaços urbano e agrário, os centros e periferias - e os processos de regionalização e sua relação com a construção das identidades. Esse posicionamento diante do mundo implica ainda em:

[...] conceber o espaço geográfico como sendo estrutura - e, a partir disso estudar sua organização, seus elementos seus objetos, etc. - e, também como experiências: as posições que os indivíduos e grupos sociais ocupam, bem como as relações que eles vivenciam, condicionam trajetórias sociais que são, também, trajetórias espaciais, o que nos permite apontar as inscrições socioespaciais de indivíduos e grupos como sendo experiências espaciais das relações sociais, econômicas e de poder. (SANTOS, 2007, p.29)

Compreender o espaço como estrutura/experiência significa entendê-lo, ao mesmo tempo, como materialização das relações econômicas e políticas - sendo este, por excelência, um instrumento de poder através do qual se dão as disputas territoriais e também como o lugar da experiência, das práticas espaciais cotidianas onde são produzidos os sentidos e os significados dos sujeitos com o espaço. Tais práticas espaciais se subjetivam e produzem memórias e identidades com os lugares de vivência, que, uma vez incorporados, se traduzem nos corpos. Nessa perspectiva, o espaço congrega uma dimensão material e também simbólica, ou seja, o sentido e o significado que os sujeitos constroem na sua relação com o espaço, bem como as práticas espaciais e as suas representações.

A consciência do papel que essas dimensões espaciais ocupam na nossa existência como sujeitos no mundo nos colocará diante de uma justiça social em que o direito ao espaço, seja no campo ou na cidade, é um direito sem o qual a condição cidadã ficará comprometida. Partindo dessa compreensão a Geografia torna-se um saber estratégico, pois como afirma Ruy Moreira, trata-se de uma ciência que tem o papel de desvendar as máscaras sociais.

\section{$\underline{\text { Notas }}$}

1 - Esse artigo é fruto das ações e reflexões desenvolvidas na linha de pesquisa, "cidade, política, cultura e processos formativos", das experiências vivenciadas por meio dos projetos desenvolvidos nas escolas públicas da rede estadual e municipal de Niterói-RJ, bem como das questões geradas a partir dos estágios supervisionados.

2 - Thomas Humphrey Marshall: sociólogo britânico, atribuiu o desenvolvimento da cidadania como desenvolvimento dos direitos civis seguidos dos direitos políticos e dos direitos sociais nos séculos XVIII, XIX e XX, respectivamente. Introduziu o conceito de direitos sociais, sustentando que a cidadania só é plena se é dotada de todos os três tipos de direito e esta condição está ligada à classe social.

3 - A respeito da dialética entre a formação social e o espaço, ver MILTON, S. A Natureza do Espaço: técnica e tempo, razão e emoção. São Paulo: Hucitec, 1996; e GOMES, P. C. C. Geografia fin de siècle: o discurso sobre a ordem espacial do mundo e o fim das ilusões. In: CASTRO, I. GOMES, P. C., CORREA, R. Explorações Geográficas. Rio de Janeiro: Bertrand Brasil, 1997. 
4 - Os grandes latifúndios e a grilagem legalizada das terras são a realidade dessa desigualdade e da aliança do atraso que persiste e se renova ao longo dos séculos no Brasil. Ver OLIVEIRA, A.U.(1990), MARTINS, J.S (1999, 1991).

5 - Uma preocupação constante do autor é a garantia de um caráter geográfico no tratamento da temática da cidadania.

6 - Tratar aqui dos meandros da elaboração de tais documentos fugiria ao escopo desse artigo. Contudo, deixamos aqui assinalada a crítica à forma política, prática e ideológica - e seus reflexos em toda estrutura do ensino - surgidas a partir da década de 1990 com os documentos oficiais.

7 - A cidadania é conceito central nos referidos documentos, encontra-se também nas primeiras páginas dos PCN de outras disciplinas, como História e Ciências; não pertence a nenhuma disciplina em particular, juntamente com outros temas crucias ética e pluralidade cultural - ganhou o sentido de transversalidade ao perpassar todas as disciplinas.

\section{Referências bibliográficas}

BEZERRA, Amélia Cristina Alves \& FEU, Rosane. Espaço e cidadania: pensando a relação entre geografia escolar e o direito à cidade. In: Encontro Nacional de Práticas de Ensino de Geografia - ENPEG, 2013, João Pessoa. FORMAÇÃO, PESQUISA E PRÁTICAS DOCENTES: REFORMAS CURRICULARES EM QUESTÃO, 2013. p. 984-994.

BRASIL. Secretaria de Educação Fundamental. Parâmetros Curriculares Nacionais : História, Geografia/ Secretaria de Educação Fundamental. - Brasília: MEC/SEF, 1997.

- Senado Federal. Lei de Diretrizes e Bases da Educação Nacional: $\mathbf{n}^{\mathbf{0}}$ 9394/96. Brasília: 1996.

CANCLINI, Nestor García. Diferentes, desiguais e desconectados. 2. ed. Rio de Janeiro: Editora UFRJ, 2007.

Consumidores e cidadãos: conflitos multiculturais da globalização. Rio de Janeiro: EDUERJ, 1996

CARLOS, Alessandri Carlos. O espaço urbano: novos escritos sobre a cidade. São Paulo: FFLCH, 2007, 123p.

O lugar no/do mundo. São Paulo: FFLCH, 2007.

CARLOS, Alessandri Carlos Ana Fani Alessandri; SOUZA, Marcelo Lopes \& SPOSITO, Maria Encarnação Beltrão (Orgs.). A produção do espaço urbano: agentes e processos, escalas e desafios. São Paulo: Contexto, 2011.

CARVALHO, José Murilo de. Cidadania no Brasil: o longo caminho. 3. ed. Rio de Janeiro: Civilização Brasileira, 2002.

CAVAlCANTI, Lana Souza. A Geografia escolar e a cidade. São Paulo: Papirus, 2008.

ANAIS DO I SEMINÁRIO NACIONAL: CURRÍCULO EM MOVIMENTO - Perspectivas Atuais. Belo Horizonte, novembro de 2010.

CRUZ, Valter Carmo. Das lutas por redistribuição de terra às lutas pelo reconhecimento de território: uma nova gramática das lutas sociais? In. ACSELRAD, Henri (Org.). Cartografia social, terra e território. Rio de Janeiro: Universidade Federal do Rio de Janeiro. Instituto de pesquisa e Planejamento Urbano e Regional, 2013.

CHAUÍ, Marilena. A reforma do ensino: refazendo a memória. Cópia mimeo, s/d. 
- Cultura e democracia. En: Crítica y emancipación: Revista latinoamericana de Ciencias Sociales. Año 1, n.1 (jun. 2008). Buenos Aires: CLACSO, 2008.

GOMES, Paulo César da Costa. A condição urbana: ensaios de geopolítica da cidade. Rio de Janeiro: Bertrand Brasil, 2002.

Geografia fin de siècle: o discurso sobre a ordem espacial do mundo e o fim das ilusões. In: CASTRO, Iná Elias; GOMES, Paulo Cesar da Costa; CORREA, Roberto Lobato (Orgs). Explorações Geográficas. Rio de Janeiro: Bertrand Brasil, 1997.

LACOSTE, Yves. A Geografia: isso serve, em primeiro lugar, para fazer a guerra. Campinas, Papirus, 1988, capítulos selecionados, p. 21-35, p. 53-58 e p. 189-195.

LEFEBVRE, Henri. La presencia y la ausencia: contribución a la teoría de las representaciones. México: Fondo da Cultura Económica. 1983.

O direito à cidade. Tradução de Rubens Eduardo Frias. São Paulo, 1991.

LEITÃO, Gerônimo. Dos barracos de madeira aos prédios de quitinetes: uma análise do processo de produção da moradia na favela da Rocinha ao longo de cinquenta anos. Tese (Doutorado em Geografia). Programa de Pós-Graduação em Geografia, Universidade Federal do Rio de Janeiro, 2004.

LESTEGÁS, Francisco Rodriguez. A construção do conhecimento geográfico escolar: do método transpositivo à consideração disciplinar da Geografia. In: MUNHOZ, Gislaine Batista; CASTELLAR, Sonia Maria Vanzella (Orgs.) Conhecimentos escolares e caminhos metodológicos. São Paulo: Xamã, 2012.

MAGALHÃES, Marcelo de Souza. História e cidadania: por que ensinar História hoje? In: ABREU, Marta.; SOIHET, Raquel. (Orgs.) Ensino de História: conceitos, temáticas e metodologias. Rio de Janeiro: Casa da Palavra, 2003.

MARTINS, José Souza. Expropriação e violência: a questão política do campo. 3. ed. São Paulo: Hucitec, 1991.

O poder do atraso: ensaios de sociologia da história lenta. 2. ed. São Paulo: Hucitec, 1999.

MARSHALL, Thomas Humphrey. Citizenship and social class and other essays. Cambridge: Cambridge University Press, 1950.

MOREIRA, Ruy. Pensar e ser na geografia: ensaios de história, epistemologia e ontologia do espaço geográfico. São Paulo; Contexto, 2007.

OLIVEIRA, Umbelino. Ariovaldo. Modo capitalista de produção e agricultura. 3. ed. São Paulo: Ática, 1990.

PORTO-GONÇALVES, Carlos Walter. A geograficidade do social: uma contribuição para o debate metodológico para os estudos de conflitos e movimentos sociais na América Latina. In: SEOANE, José. Movimientos sociales y conflito en América Latina. Bueno Aires: CLACSO, 2004, p. 1-11.

SANTOS, Milton. Espaço e sociedade. Petrópolis: Vozes, 1979.

O espaço do cidadão. Coleção Espaços. São Paulo: Nobel, 2012.

1996;

A natureza do espaço: técnica e tempo, razão e emoção. São Paulo: Hucitec,

SANTOS, Renato Emerson (Org.). Diversidade, espaço re relações étnico-raciais: o negro na geografia do Brasil. Belo Horizonte: Autêntica, 2007.

SENNETT, Richard. Carne e pedra: o corpo e a cidade na civilização ocidental. São Paulo: Record, 1997.

. O declínio do homem público. Rio de Janeiro: Companhia das Letras, 1988

SOJA, Edward. Geografias pós-modernas: a reafirmação do espaço na teoria social crítica. Rio de Janeiro: Jorge Zahar, 1993. 